\title{
Professionals unprepared: An appraisal of social work practice at the Drugs Abuse Rehabilitation Centres in Khyber Pakhtunkhwa, Pakistan
}

\author{
Shakeel Ahmad ${ }^{1} \mid$ Abida Bano*2 \\ 1. Department of Social Work, University of Peshawar, Peshawar, Pakistan. \\ 2. Institute of Peace and Conflict Studies, University of Peshawar, Peshawar, Pakistan.
}

*Corresponding Author Email: abano.78@gmail.com | abidabano@ uop.edu.pk

Published: August 29, 2021

\begin{abstract}
Social work is a practice-based profession that facilitates, enables, and rehabilitates the neglected segments of society facing various issues, including substance abuse. However, social workers' efficiency in the drugs rehabilitation centres is constrained by several factors. This study examines the medical social workers' role in providing institutional service delivery in substance (drugs) abuse treatment centres. This paper relies on qualitative approaches. The primary data collection methods used are observation and in-depth individual interviews with the selected research participants from the drug treatment centres. The study found that the social work theory and practice gap hurts services delivery in Drug Abuse Treatment Centres (DATCs). Lack of updated content and indigenous philanthropy models, the medical social workers do not adequately meet the requirements of DATCs. Donor-driven drives and demotivated social workers augment the services delivery crises at the DATCs. Besides, formalizing the medical social work career structure and broadening institutional support could remedy the flawed and weak social welfare practice in drugs rehabilitation services.
\end{abstract}

Keywords: drug addicts, drug addicts' treatment centres, social workers, medical social worker, social work, philanthropy, medical social work, indigenous philanthropy.

\section{How to Cite:}

Ahmad, S. \& Bano, A. (2021). Professionals unprepared: An appraisal of social work practice at the Drugs Abuse Rehabilitation Centres in Khyber Pakhtunkhwa, Pakistan. Journal of Humanities, Social and Management Sciences (JHSMS), 2(1), 108-120. https://doi.org/10.47264/idea.jhsms/2.1.10

\section{Publisher's Note:}

IDEA PUBLISHERS (IDEA Journals Group) stands neutral with regard to jurisdictional claims in the published maps and institutional affiliations.

\section{Copyright:}

(C) 2021 The Author(s), published by IDEA PUBLISHERS (IDEA Journals Group)

This is an Open Access article published under the Creative Commons Attribution-NonCommercial 4.0 International License (http://creativecommons.org/licenses/by-nc/4.0/) 


\section{Introduction}

Social work is a practice-based profession that facilitates, enables, and helps the unaided population, especially the neglected segments. Social work has been defined as using various scientific methods to help people in need (Mitchell, 1974). Thompson (2020) notes that social work involves wellness and rehabilitation of specific categories of the population. Studies of (Pawar \& Anscombe, 2014) and Midgely (2001) show that social work education and practice have developed the education standards transnationally. Shah (2015) argues that social work programs played a significant role in bringing social change and solving relationship problems. However, the growing disparity, poverty, and inequalities worldwide have made it difficult for social work graduates to respond to the situation effectively (Soliman \& Abd Elmegied, 2010).

The concept and practice of contemporary social work emerged in the 19th century in Western Europe and North America (Atal, 1981), which later transplanted into developing societies of Asian and African countries, however, completely ignored the local and indigenous sources of social welfare (Gray et al., 2008; Healy, 2001; Lyons, 1999; Midgely, 1981; Ragab, 1990). Sticking to the colonial literature means that western developed society is the only source of civilization, which guides ways and means of doing something right to people in need. These beliefs completely negate the strengths and potential of the local, indigenous, and essential welfare practices, Khair khegara, ${ }^{1}$ to help each other.

Applying conflict theory, the existing theory and practice of social work, directly and indirectly, support the 'powerful segment of society,' i.e., bureaucrats, elites of the National and International NGOs, feudal lords as legislators by helping and enabling not the poor instead an elite segment of society (Bartos \& Wehr, 2002). It is an empowering tool for sustaining and promoting colonial and imperials forces in the name of welfare in Pakistan. According to the Critical Elite theory of Wright Mills, there is an elite power group (bureaucracy, military) and managerial class (highly paid INGOs) who share favours and have decision-making power that affects the lives of others. In this exchange of favours among power-elite, the poor get poorer while the rich get richer (Haralambos \& Holborn, 1991).

The need to introduce social work and social welfare was felt in theory and practice soon after Pakistan's creation; hence, readymade short-courses and social policy mechanisms were presented with the U.N.'s support in Pakistan in 1953. These courses and policy mechanisms were introduced in Europe and America in the late 19th century to meet their countries' challenges. However, it is still a challenge for Pakistan to become a self-reliant welfare state on the "Model of Madinah State." ${ }^{2}$ Though Pakistan has its indigenous social welfare mechanism, which could play an active role in healing the issues of vulnerable segments, such challenges have never been acknowledged and addressed seriously, neither at the social work curriculum nor in social welfare policymaking. Moreover, this adopted social work model from the United States of America is still an impediment to overcome social problems at different levels of interactions.

Resultantly, social welfare structure and degree program flourished in 1956, and the methods of social work such as social casework, social group work, community development were introduced in the different universities of Pakistan, such as in the University of Punjab in 1954, the University of Karachi in 1961, the University of Sindh in 1966, the University of Baluchistan in 1974 and the University of Peshawar in 1976. According to Kulkarni (1979), 
Professionals unprepared: As appraisal of social work practice at the Drugs Abuse ...

social casework, social group work, community organization, and medical social work were adopted by India from American Social Work syllabi; hence, Pakistan was not an exception.

As per Higher Education Commission Pakistan (2014) policy, the Bachelor's and Master of Arts degree programs in social work are credit-based at the Universities and higher education institutes. Many colleges offer specializations such as human resource and personal management, community development, medical/hospital social work (Hassan, 2016). Medical social work refers to the branch of social work, which is especially interested in providing services to people suffering from psychosocial problems (Ali \& Rafi, 2013). Like other social work branches, medical social work is still rudimentary in Pakistan (Shah, 2015; Riaz, 2016).

At the initial stages of medical social work in Pakistan, medical social workers were trained in the profession. As a result, 90 medical social worker units were established in Punjab, 29 in Sindh, 4 in Baluchistan, and 4 in Khyber Pakhtunkhwa (Ali \& Rafi, 2013, p. 358). However, there were no special arrangements for pre-service and in-service training of the medical social workers (Ali \& Rafi, 2013). The only platform available for social workers' orientation and training is the teaching departments of social work in Pakistan's public and private sector universities. However, universities' training lacks the indigenous knowledge and practice of social welfare, which society has practiced for a long time.

The dilemma of ignoring on-ground and local realities in medical social work has also been realized by Shireen (2002), a pioneer social worker in Pakistan. The concept and practice of medical social work are not new; instead, it was introduced in 1953, just about six years after Pakistan's creation. (Shah, 2015, Hassan, 2016). Nevertheless, studies show that medical social work could not be practiced in Pakistan in the same manner as in the West, where social assistance was available to help patients (Hassan, 2016; Ali \& Rafi, 2013; Shireen, 2002). On a one-to-one basis, the casework approach did not suit our family culture, where everyone got involved with the patient's problems. The reasons could be the inability to buy medicines, rehabilitation, family problems, and health education. The Medical Social Worker's role and his/her training had to respond to these basic needs (Shireen, 2002, p. 291).

\subsection{Medical social work and drug abuse treatment and rehabilitation services}

According to the United Nations Office on Drugs and Crime (UNODC) country profile report on Pakistan, some over six million adults are substance dependent, wherein around four million are addicts. ${ }^{3}$ According to reports generated by civil society, the drugs problem has escalated after the war on terror started in 2001 - the U.S. led the war against Al-Qaida to eliminate the latter's sanctuaries in Afghanistan. However, this war expanded to Pakistan once the militants crossed the border between Pakistan and Afghanistan to infiltrate erstwhile FATA, formerly Federally Administered Tribal Areas (FATA). The effects did not stay in just erstwhile FATA but spread to all Khyber Pakhtunkhwa province, significantly Peshawar's provincial capital. Drugs trafficking has also augmented the global militarization in the Pakistan-Afghanistan borderlands. Bukhari and Haq (2011) reported that there were 4.6 million drug addicts in Pakistan around 2008. Within Peshawar city, Asad (2011, p. 20) said that 504 drug addicts were referred for detoxification and treatment to DATCs in the public hospitals of Peshawar city. However, the numbers have multiplied over time and have become a challenge for the Pakistani government to address it with limited resources. Medical Social Workers (MSWs) lay a vital role in addressing drug user's related issues alongside the healthcare department. 
However, lack of professional training and an inadequate understanding of the contextual social welfare models, MSWs are not as effective as expected be.

Due to multiple problems, MSWs are unable to provide effective rehabilitative services to substance users. Therefore, $45 \%$ of the treated substance users get a relapse. This is also associated with a shortage of medical social workers. Doctors, psychiatrists, and psychologists play a significant role in treating drug addicts; however, ignoring the part of medical social workers results in a further escalation of relapse. The magnitude of the challenges and the vast number of relapse cases raise the need to examine the issue and show the factors responsible. Thus, the present study investigates the problems in medical social work service delivery, focusing on drug addicts' treatment and rehabilitation in Khyber Pakhtunkhwa.

\subsection{Research questions and objectives}

The study asks the research questions as: a) What problems do MSWs face while delivering social work services at the DACTs? b) Why do medical social workers lack recognition and due status in the social welfare and health sectors in Khyber Pakhtunkhwa? c) How and why do the theory and practice gap affect the practitioners in the field? The research article explores the gaps in social work theory and practice but primarily focuses on the problems faced by MSWs while providing social welfare services at the DATCs. Furthermore, the study evaluates the services delivery at the selected DATCs in Peshawar to question the lack of recognition of social workers' role in social welfare and health sectors and examine the underlying causes.

\subsection{Rationalizing the study}

Medical social workers play a crucial role in providing psychosocial services to the trauma affected, drug abusers, and different patients alongside the health care professionals at the health care centres. Besides other hospital sections, MSW plays a vital role in rehabilitating the substance users in Pakistan's various drug abuse treatment centres. However, medical social work in Pakistan must be redefined to address drug addiction problems here. The magnitude of drug addiction is remarkably high globally, including in Pakistan. According to the UNODC report 2020, 269 million people used drugs in 2018, which has increased to over 35 million as per recent statistics. ${ }^{4}$ The rapid increase in drug use asks for utilizing and allocating more resources to address the issue. Also, it asks for applying indigenous methods in sync with the medical care (Ibrahim et al., 2020)

According to a 2013 survey by UNODC, over 4.25 million people were drug addicts. As per the recent statistics, the number of drug users has increased to 6.7 million, making it one of the highest number countries in the world. ${ }^{5}$ In such circumstances, the significance of medical social work cannot be ignored. It plays a bridging role between the patient and hospital management by mobilizing various welfare resources for ensuring mental health support to the patient and his/her family members. Medical Social Workers also assist patients in availing financial support from the Zakat Fund and Pakistan Bait-ul-Mal for treatment (Ali \& Rafi, 2013, p.358). However, despite the critical role that the MSWs play in drug treatment centres, very few studies critically analyse the level of professional training and delivery of MSW at DATCs. Thus, the present study attempts to bridge the gap in the literature. Also, it forwards some suggestions as to how to improve the professionalism and professional training among MSWs to enhance their role in substance users' rehabilitation in society. 
Professionals unprepared: As appraisal of social work practice at the Drugs Abuse ...

\section{Research methodology}

The study adopts the qualitative approach and employs discourse analysis (Laclau \& Mouffe, 1985) to examine the discrepancies in acknowledging the role of trained social workers for substance users. Also, it investigates the contributions of local academic institutions in training human resources in social work to address the help addressing the problems of vulnerable segments in Pakistan. There are various ways to conduct discourse analysis, among which Foucauldian discourse analysis is widely used. Hence, this paper draws on discourse analysis informed by the poststructuralist approaches that appreciate structure's role in creating meanings in the social world. A non-probability sampling - purposive sampling technique is used to select the study participants.

The study uses the data collected from research participants, divided into two categories. Firstly, a total of 15 in-depth interviews were conducted with the senior professionals and social medical officers who worked in the state-run Drug Addicts Treatment Centres in Peshawar. Secondly, another set of five in-depth interviews were conducted with the experts accomplished professors/educationists in academia who have been engaged with the subject for long enough to understand the issues around theory and practice and its consequences in the practical field. The in-depth individual interviews aim to examine the role of professional social workers in understanding the challenges faced in providing institutional service delivery in different substance use treatment centres in Khyber Pakhtunkhwa, Pakistan. Additionally, the paper applies triangulation of measures for verification purposes; thus, an observation also makes part of the research methods used.

\section{Critical analysis}

In Pakistan, professional social workers are in the prison of state-sponsored welfare institutions based on red-tapism and bureaucratic mechanism principles. Such institutions as welfare homes, child protection centres, juvenile prison, specialized education centres, and substance users' rehabilitation centres have a feeble and fragile management and administration structure with inadequate intervention, job structure, and financial status (Ahmad \& Bano, 2020; Khan et al., 2019). The field reflections and observations of such professional social workers never guide research, curriculum, and pedagogy. The post-traumatic effects disable social work researchers from portraying the strengths and weaknesses of social work in Pakistan, ultimately producing 'academic parasites.' The irony is that the concept and practice of medical social work are not new; instead, it was introduced in 1953, just about six years after Pakistan's creation. (Shah, 2015, Hassan, 2016). Almost after over fifty years, the gap between theory and practice could not be bridged, still hurting the standard of social welfare services that the MSWs offer at the DATCs. The following themes are vital to discussion on lack of connection between social work theory and practice and its impact on the effectiveness of MSWs at the DATCs.

\subsection{Mismatch of theory and practice in social work}

As per the study findings of the study, a wide gap exists between the theory and practice of social work in Pakistan. Social work teaching research, pedagogies, and curriculum do not adequately address the needs of society; hence, proper designing and updating. The subjects and sources taught in the higher education departments do not provide the required expertise and practical training necessary in medical social work (Shah, 2015). Lack of quality research 
and theoretical orientation jeopardizes the policymaking initiatives in Pakistan. Moreover, the social welfare policy in Pakistan lacks timely updating and innovation, which in turn negatively affects the implementation.

The Pakistani government has implemented several social welfare programs for the masses, but the lack of coordination among the departments has marred the intended outcome of the programs. Most of the respondents agreed that the welfare initiative operates in a less coordinated manner for various reasons. For instance, Pakistan Bait-ul-Mal, social welfare departments, employees' social security schemes, various social protection programs such as Benazir Income Support Program (BISP) have no coordination. If these programs were run in a coordinated manner by specialists trained in social theory and practice would have a tangible outcome. Being a Muslim country, Pakistan needs to have social work models informed by the wider population's beliefs. In countries where religious beliefs are essential, social work needs to be modern but respectful of the country's religious values, lacking which would affect social work practices (Crisp, 2015; Carlsen, 2015; Cree, 2013). This is only possible when social work students are correctly oriented with the culture, context, and indigenous social welfare models through their taught programs.

Initially, in the early days of 1953, the U.N. expert convinced Pakistan's government regarding the importance of medical social work. However, due to the missing link between the teaching institutions and welfare policymaking bodies, the government would not know much about the role and importance of MSW. Medical professionals used this negligence against the social workers pleading that there is no need for social workers in the health sector. It is very alarming for the social work education and social welfare policy that such an important branch of social work is declared as a 'dying cadre' in a province where drugs addiction is on the rise and resources are extremely limited to cater to this colossal issue (UNODC Report, 2021). ${ }^{6}$ Another senior social, medical officer shared during an in-depth interview as,

The future of the MSW, DATC, and substance users is incredibly dark. I am anxious about the MSW's future and the substance users, as doctors and other medical practitioners are incredibly limited and somewhat hostile too. They diagnose their medical symptoms and provide treatment accordingly. Nevertheless, as far as behaviour modification is concerned, they behave very harshly. Dealing with substance users requires a lot of patience and training."

The experts noted that, in theory, the concepts taught have no link with reality. For instance, during fieldwork, one of the fundamental questions that the experts, both teaching and the professional MSWs, is how they define social work? Several discourses emerged in interview responses entailing, social work is a helping profession (teachers and practitioners) that empowers, brings social change, and provides professional help alongside philanthropy and charity. Social work aims to serve humanity beyond the divisions of caste, colour, or country and eradicate social problems, among others. Moreover, it is an action-oriented discipline and profession in Pakistan, based on the fieldwork during academic training. Scholars endorse that social worker plays a critical role in providing services to the children and youth in health care, people with disabilities, destitute and marginalized sections of society.

The narratives shared by the respondents also resonated with the IASSW and IFSW (2014) definition of social work that underscores it as a practice-based discipline that works for 
Professionals unprepared: As appraisal of social work practice at the Drugs Abuse ...

liberation and empowerment of people. Additionally, it addresses life challenges and ameliorates well-being by engaging people and institutions (Ibrahim et al., 2020; Ibrahim, 2018). Undoubtedly, social work is a helping, enabling, and empowering field and professional, but such narratives suit the developed countries where the professional associations provide adequate services to the people in society. However, countries in South Asia, including Pakistan, have unique cultures and social institutions, making it difficult to impart social work services when required (Pulla et al., 2020; Nikku, 2014).

Nevertheless, due to the missing relationship between social work theory and practice, social work is losing its specialized branches in the market, reducing the scope of social work education in Pakistan. The lack of connection between theory and practice affects the standard of services that the MSWs provide and debilitates the overall situation of drug users and substance users at the DATCs. A serious effort is required on the part of the government, academia, and civil society to redesign the medical social work course at the Universities

\subsection{Lack of indigenous knowledge regarding social welfare practice}

The empirical evidence shows that the role of MSWs, especially in substance use rehabilitation, is severely constrained due to no awareness of the indigenous knowledge repositories of social welfare practices. In post-colonial countries such as Pakistan, the idea, but not practice, of social work models is generally imported from the developed capitalist countries. Such transplanted ideas create considerable challenges to those who are trying to translate them into practice. Indigenous knowledge refers to local, traditional, aboriginal, or 'oriental' understanding and explanation based on local beliefs, practices, customs, and worldviews (Hoppers, 2005, p. 2). It is also defined as the knowledge and skills people in a particular geographic area possess, enabling them to get the most of their environment (Hoppers, 2005, p. 2). Scholars agree that the adaptation of 'western knowledge' is a threat to 'cultural autonomy' (Horsthemke, 2008, p. 129). Western cultural and colonial influence has subjugated diverse, local, and contextual knowledge through cultural hegemony (Hoppers, 2005, pp. 8, 14).

Pakistan has a rich history of social welfare and support systems for the lower segments of society. These welfare and support systems are based on cultural and religious principles such as zakat, charities, khairat, sadqaat, fithrana. These abundant resources have recently been recognized to establish the 'Pakistan Centre for Philanthropy,' which provides accreditation to an organization that runs through indigenous charities. Scholars agree that indigenous models of philanthropy are effective (Axelrad, 2011). According to the Pakistan Centre for Philanthropy (2015) survey, 240 billion contribute as charity annually in Pakistan (PCP, 2015). Similarly, private sector donations raised from 230 million to 6.9 billion (PCP, 2015).

Similarly, many developed countries have also initiated such models of social welfare not long ago. For instance, in 2008, the U.S. government registered around 120,000 charity organizations with the Internal Revenue Services. Besides, almost 30,000 such organizations in Britain and 15,000 in Germany provide services to the communities (Preston, 2008). There is a need to identify such indigenous sources of philanthropy, collection mechanism, and utilization of such resources for society's welfare. Local concepts, terminologies, and application methods need to incorporate into the curriculum and course of social work taught at various universities of Pakistan. For instance, during an in-depth interview, a senior social medical officer stated: 
"Usually, we apply psychological counselling and therapy techniques, but the most effective one is present in the Pashtun culture and the religious belief system. We call it local therapies and spiritual counselling. For instance, we share with substance users that drugs are prohibited in religion; however, Iradaa/niyaat $^{7}$ (intension or motive) and Taubah (repentance) not only cleanse you physically but spiritually too. Allah will forgive your transgressions. Similarly, in cultural therapy, we use Pakhtun cultural notions such as Izaat (honour) and Azaadi (freedom) as the key principles of life. Due to addiction, you lose honour and freedom, and the best way to restore it is by giving up this addiction. These therapies work miraculously with some patients and have a remarkable impact on substance users' rehabilitation and relapse prevention in our wards" (Field reflections).

Yusuf (2020), resonating with the study findings, argues that spiritual, cultural practices go hand in hand with the western ways of treating mental health problems in Pakistan. People attach salience to these cultural, spiritual reasons and practices that might prove helpful in treating the patients. However, researchers and teaching departments never realized and explored such indigenous sources of support. The concepts taught at departments do not match the requirements of the practices. Further, most of the social work practices in Pakistan are donor-driven, encouraging dependency syndrome among policymakers and practitioners. Resultantly, social work professionals feel demotivated in the process of service delivery.

\subsection{Medical social work - a 'dying cadre' in Pakistan}

Most of the respondents noted that the MSWs are bridging between the needy patients and the various resources required for their complete recovery. Due to the disconnect between theory and practice and lack of indigenous knowledge about the social welfare mechanisms, the MSWs restrict themselves to file work; consequently, the social worker's fundamental role has never been seen by society. Moreover, no in-service training programs have been imparted to social professionals; it has lost their importance. According to a senior social medical officer who shared his experience during an in-depth interview as:

"Medical social work is like a dying cadre in the Khyber Pakhtunkhwa since 2005 when the Musharraf's government decided that the seat will be abolished, and no fresh hiring will be made if an MSW retires. At that time, the medical social workers were demanding promotions; however, it was accepted by the government with the condition that the post would not be advertised after their retirement" (Field Reflections).

It is unfortunate that in most cases, the senior social workers who get retired, their position will be abolished after retirement. Similarly, in the health sector, medical social work is declared as a dying cadre. In comparison, the vitality of MSC testifies its core objective, which is to help patients understand their problems and motivate them to work toward the solution that is only possible when medical social work is brought under formal career structure in the government sector (Ali \& Rafi, 2013). Lack of incentives for trained medical social workers discourages able and competent people from joining the government-run drug abuse centres. If the curriculum includes the structure and job description of a medical social worker, it will clarify many ambiguities around the nature of work. 
Professionals unprepared: As appraisal of social work practice at the Drugs Abuse ...

Additionally, MSWs require analytical and conversational skills to develop rapport with the patients (Hassan, 2016). To bring the services of DATC, new and updated theory with contextual sensitivity is vital to the social work discipline and practice. There is more reason to revive medical social work since most of the burden of mental health patients is shifted to the hospitals than asylums (Afridi, 2008).

\subsection{Red-tape and delaying tactics in services delivery}

One of the critical factors responsible for the weak social work practice is the delaying tactics of bureaucracy. Bureaucratic heads tend to red tape the promotion cases of the MSWs, which discourages many from leaving the sector for better prospects. For instance, one of the senior social medical officers shared during an in-depth interview, "I got promotion after a personal struggle, and even I bribed secretariat staff for expediting my promotion case." The respondents noted that lack of accountability had emboldened the bureaucracy to use delaying tactics and impact their career negatively.

Resultantly, the social work professionals feel demotivated in the process of service delivery. It is further reinforced by red-tape, a challenge primarily concerned with the bureaucratic delay in implementing policy-related measures/practices. The outcome of such official and nonofficial problems contributes to a general sense of lethargy among professionals, which severely affects their work. The study suggests a broadening of institutional focus towards exploring informal sources of social welfare to bridge the knowledge gap between field professionals and a society's socio-cultural needs, a site for the implementation of welfare programs. This realization was particularly inspired by studying the institutionalized forms of charities and philanthropies found in welfare and charity organizations like Edhi Foundation and Shaukat Khanum Memorial Hospital.

According to Marshal (1963), human equality is the basic principle of a democratic and welfare state associated with full membership in a society or community. Human equality stress state role in excluding excluded class like destitute people into mainstream society through three legal rights civil rights, political rights, and social rights. The state must ensure the welfare rights of citizens without any hurdles and complications. However, red-tapism is one of the significant obstacles in executing policies in developing countries like Pakistan. Such a mechanism typically gives birth to lethargy among professionals, which affects their work. According to Free Dictionary (Farflex), red-tapism refers to excessive paperwork and complicated procedures before any action. 'Clientelism' mostly prevails in the political and administrative system, based on feudal and tribal values (Kalia, 2013). Civil and military bureaucracies make policies and decisions, which provides less space for democratic bodies, which incompetent politicians generally fill during democratic regimes (Kalia, 2013). Welfare administration and departments have always encountered such complications.

\subsection{High ratio of relapse among the substance users}

MSWs encounter not only capacity-building problems but also bleak careers in Pakistan. Medical social workers receive high numbers of addicts in their DATC units, where they provide rehabilitative services. However, the services remain ineffective due to a lack of financial, technical, and human resources. One of the alarming issues highlighted in the research is that $45 \%$ of addicts have relapsed, whereas the experts think that one year after 
stopping opiates, there is a 30 and $85 \%$ chance of relapse (Asad, 2011, p. 29). There is a need to reform Pakistani laws on drugs to discourage the increasing drug trade (Uddin \& Rehman, 2020). One of the respondents said:

"This high relapse ratio is due to the inefficient health delivery system coupled with the inadequate capacity of medical social workers to provide detoxification for ten days to the maximum."

Though the government is spending a lot on establishing and maintaining the detoxification centers; however, it has not paid due attention to the recruiting, capacity building, and promotion of the medical social workers (Asad, 2011, p. 31). According to a senior social medical officer:

"We have established DATC units compared to Dost Foundation - a private DATC, but they are active based on enough resources and trained human resources" (Field reflections).

The findings the study testify that one of the reasons for relapse among the substance users is the lack of well-trained MSW at the DATCs. Additionally, the number of MSWs present at the DATCs does not correspond to the influx of patients. Thus, the inadequate and insufficient services at the DATCs cause the relapse. Moreover, on the ground, the social workers work in very disempowering and distressing situations in the Khyber Pakhtunkhwa. The social worker employed in the public sectors have no job structure, no resources, and bureaucrats are in the social policymaking position. For instance, one of the senior social workers stated her experiences:

"I have served this department for 26 long years and will be retiring in grade 18 next year. My class fellows who joined other departments in the same year will retire in grades 20 and 21, but I could not get a promotion due to a lack of job structure. Denial of due and deserved promotions badly affects the efficiency of the staff members and block the talented human resources from being inducted. Those staff members who are competent often leave the institute to join other departments."

Studies conducted on the role of MSWs also reiterate that the number of MSW needs to increase along with a career structure and benefits, which could share the burden on the health care system (Ali \& Rafi, 2013). Also, relapse among drug users happens due to their inability to handle social stress and adjust skills (Batool et al., 2016). In which case, medical social workers help the drug user patients to recover early (Ali \& Rafi, 2013)

\subsection{Conclusion and recommendations}

Social work practice being vital in rehabilitative services for drug users is desired and needed in Khyber Pakhtunkhwa, where resources are meagre to address the psychosocial health problems of substance users. Unfortunately, due attention is not paid to the social work education and practice in tandem, causing severe problems for the medical social work practice in the country. Lack of resources allocation, no updated curricula at the HEIs, and a missing link between government and academia are prominent issues that need immediate addressing. 
Professionals unprepared: As appraisal of social work practice at the Drugs Abuse ...

MSW is more important than the other branches of social work for its crucial supportive role in the health care system.

MSW plays a vital role in rehabilitating drug addicts who depend on social services for a more extended time before going back to society, but the health care system cannot afford to spare resources for their complete psychosocial rehabilitation. Despite the importance of MSW at the DATCs, it is one of the 'dying cadres' that needs resuscitation to reduce some burden from the health care system. Spiritual healing practices prevalent in Pakistan are essential aspects of social welfare services and need to be mainstreamed through the syllabus at the HEIs. Moreover, indigenous social welfare models practiced in society for centuries could also prove a great resource if incorporated into the curricula.

The study forwards a few recommendations for the uplift of the social work discipline and practice and their due place in the health care profession:

- The study recommends a broadening of institutional focus towards exploring informal sources of social welfare to bridge the application gap between field professionals and the socio-cultural needs of society. A realization inspired the institutionalized forms of charities and philanthropies like Edhi Foundation and Shaukat Khanum Memorial Hospital in different parts of Pakistan. There is an immense need for tailoring these concepts into the curriculum as we learned the norms and values of society but never talked about these words and concepts in the curriculum. There should be such courses that reflect the indigenous culture of society.

- Moreover, there is a need for rational thought, i.e., 'out-of-the stomach," for reviewing the existing courses, literature, skill, and strengths of the human resource associated with the field. If we want to eliminate imperialism of the imported models, the local and indigenous concept and practice of philanthropy and charities must be mainstreamed into curriculum and policy mechanisms on scientific grounds.

- There is an immense need to engage intellectuals with local and indigenous wisdom in a serious debate in the national conferences for looking into the possibilities of translation and adaptation of the existing theory and practice of social work according to society's onground realities and problems.

\section{References}

Afridi, M. I. (2008). Mental health: priorities in Pakistan. JPMA. The Journal of the Pakistan Medical Association, 58(5), 225-226. https://europepmc.org/article/med/18655394

Ahmad, S. \& Bano, A. (2020). Rehabilitation of Children with Intellectual Disability: Challenges in Social Skills Training in Khyber Pakhtunkhwa, Pakistan. Liberal Arts and Social Sciences International Journal (LASSIJ), 4(1), 171-188. https://doi.org/10.47264/idea.lassij/4.1.16

Ali, M., \& Rafi, S. (2013). Medical social work in Pakistan: A multi-model approach to collaborative practice in health care settings. Academic Research International, 4(4), 355. http://www.savap.org.pk/journals/ARInt./Vol.4(4)/2013(4.4-38).pdf

Asad, Z. A. (2011). Relapse and risk behaviour among drug addicts in Peshawar, Pakistan. Journal of Criminology, 3(2), 23-31.

Atal, Y. (1981). Building a nation: Essays on India. Abhinav. 
Batool, S., Manzoor, I., Hassnain, S., Bajwa, A., Abbas, M., Mahmood, M., \& Sohail, H. (2017). Patterns of addiction and its relapse among habitual drug abusers in Lahore, Pakistan. Eastern Mediterranean Health Journal, 23(3).

Bartos, O. J., \& Wehr, P. (2002). Using conflict theory. Cambridge University.

Bukhari, H., \& Haq I. (2011). Drug trafficking and the black economy. The News International.

Carlsen, M. S. (2015). Becoming a social worker: Global narratives Viviene E Cree (Ed.). https://doi.org/10.1177/1468017314568497

Cree, V. (Ed.). (2013). Becoming a social worker: global narratives. Routledge.

Crisp, B. R. (2015). Religious literacy and social work: The view from Australia (pp. 207-226). Policy Press.

Gray, M., Coates, J., \& Bird, M. Y. (Eds.). (2008). Indigenous social work around the world: Towards culturally relevant education and practice. Ashgate Publishing.

Haralambos, H., \& Holborn, M. (1991). Sociology, themes and perspectives. Collıns Educational.

Hoppers, C. A. O., (2005). Culture, indigenous knowledge, and development: The role of the University. Centre for Education Policy Development (CEPD), Occasional Paper No. 5, 1-50.

Healy, L. (2001). International social work: Professional action in an interdependent world. Oxford University.

Horsthemke, K. (2008). The idea of indigenous knowledge. Journal of the World Archaeological Congress, 4(1), 129-143. https://link.springer.com/article/10.1007/s11759-008-9058-8

Hassan, S. M. (2016). Medical Social Work: Connotation, Challenges, and Prospects. Pakistan Journal of Social Sciences (PJSS), 36(1).

Ibrahim, Q. A., Sorur, M., Labidi, L., \& Osburn, L. G. (2020). Quality of social work education and practice in the Arab countries: a comparative study of Palestine, Qatar, and Tunisia. Social Work Education, 1-14. https://doi.org/10.1080/02615479.2020.1773781

Ibrahim, Q. A. (2018). Social work education in Arab universities and educators' perceptions. Social Work Education, 37(1), 78-91. https://doi.org/10.1080/02615479.2017.1370452

Kalia, S. (2013). Bureaucratic Policy Making in Pakistan. Dialogue (Pakistan), 8(2). 156-170

Khan, I. U., Rehman, A. U., \& Khan, N. U. (2019). Impact of the Attitude of the Jail Staff on the Juvenile Inmates. Pakistan Journal of Criminology, 11(3), 29-42.

Kulkarni, P. D. (1979). Social policy and social development in India. Association of Schools of Social Work in India.

Midgley, J. (2001). Issues in international social work: Resolving critical debates in the $\begin{array}{llll}\text { profession. Journal of } & \text { Social }\end{array}$ https://doi.org/10.1177/146801730100100103

Midgely, J. (1981). Professional Imperialism: Social Work in the Third World. Heinemann.

Mitchell, C. F. (1974). A Social Work Guide for Long-Term Care Facilities.

Nikku, B. R. (2014). Social work education in South Asia: Diverse, dynamic and disjointed. In Global Social Work (pp. 97-112). Sydney University. https://www.jstor.org/stable/pdf/j.ctv1fxm2q.11.pdf

Laclau, E., \& Mouffe, C. (1985). Hegemony and Socialist Strategy: Towards a Radical Democratic Politics. Verso Trade.

Lyons, K. (1999). International social work: Themes and perspectives. Ashgate 
Professionals unprepared: As appraisal of social work practice at the Drugs Abuse ...

Pawar, M., \& Anscombe, B. (2014). Reflective social work practice: Thinking, doing and being. Cambridge University.

Preston, H. H. (2008, September 26). The new face of private philanthropy. The New York Times. https://www.nytimes.com/2008/09/26/your-money/26iht-mphil.html

Pulla, V. R., Das, T. K., \& Nikku, B. R. (2020). Indigenous or blended model for South Asian social work? Space and Culture, India, 8(1), 40-58. https://doi.org/10.20896/saci.v8i1.773

Ragab, I. A. (1990). How social work can take root in developing countries. Social Development Issues, 12(3), 38-51. https://www.researchgate.net/publication/274705743_How_social_work_can_take_ root_in_developing_countries

Riaz, S. (2016). Development of social work as a discipline in Pakistan: An evaluation. New Horizons (1992-4399), 10(1), 31-45.

Shah, N. A. (2015). Social work teaching in Pakistan problems and remedies. New Horizons, 9(1), 93-99.

Shireen, R. (2002). Social welfare in Pakistan. Oxford University. https://catalogue.nla.gov.au/Record/2386124

Soliman, H. H., \& Abd Elmegied, H. S. (2010). The challenges of modernization of social work education in developing countries: The case of Egypt. International social work, 53(1), 101-114. https://doi.org/10.1177/0020872809348951

Thompson, N. (2020). Understanding social work: Preparing for practice. Red Globe.

Uddin, S., \& Rahman, S. U. (2020). Pakistani laws on the use of narcotics and drug addiction: Need for Reforms. Islamabad Law Review, 4(1/2), 0-8. https://www.proquest.com/docview/2530038229?pqorigsite $=$ gscholar $\&$ fromopenview $=$ true

United Nation's Office on Drugs and Crime (2021). World's drugs report. United Nations https://www.unodc.org/unodc/en/data-and-analysis/wdr2021.html

Yusuf, H. (2020). Culture and Mental Health in Pakistan. In Moodley, R., \& Lee, E. (Eds.), The Routledge International Handbook of Race, Culture and Mental Health (1st ed.). Routledge. https://doi.org/10.4324/9781315276168

\section{Notes:}

${ }^{1}$ Will be explained shortly.

${ }^{2}$ Emphasis added.

${ }^{3}$ https://www.unodc.org/pakistan/en/country-profile.html

4 World Drug Report 2020 (United Nations publication, Sales No. E. 20.) https://www.unodc.org/unode/press/releases/2020/June/media-advisory---global-launch-of-the-2020world-drug-report.html

${ }^{5}$ https://www.unodc.org/pakistan/en/drug-use-in-pakistan-2013-survey-reveals-high-levels-of-drug-useand-dependency.html

6 https://www.unodc.org/pakistan/en/unodc-world-drug-report-2021_-pandemic-effects-ramp-up-drugrisks--as-youth-underestimate-cannabis-dangers.html

${ }^{7}$ Non-English words are italicized. 